\title{
STRATEGI PENINGKATAN KINERJA BADAN KEHORMATAN DPRD DALAM PENEGAKAN KODE ETIK DEWAN
}

\author{
Helmi Nuky Nugroho \\ Universitas Negeri Semarang \\ Kampus Sekaran, Gd K Gunungpati Semarang \\ E-mail: helmi.nuky@gmail.com
}

Diterima: 24 Agustus 2016 | Direview: 29 Desember 2016 | Disetujui: 10 Januari 2017

\begin{abstract}
According to article 154, paragraph 2 of the ACT 23, 2014 the implementation of the duties and authority of parliaments is set in the code of conduct. Member of House of Representatives of District / city perform other duties according to the regulation including the code of ethics. They exercise the rights and obligations under the code of conduct. This article will analyze the role of the Honor Code Agency in the enforcement of violations committed by the council members, the factors restricting the performance of Honor Code Agency in Pemalang and the strategy to improve the Agency performance. This article is a juridical sociological research which uses a qualitative approach. Sources of research data is primary and secondary data. The techniques used are interviews, observation, and literature studies. The results showed that in carrying out the duties and authority of the Honor Agency of legislative body has an active and passive function. The active function is to evaluate each member of the Board in the meeting, to supervise legal product that is produced, reviewing the intensity of the meeting by members of Parliament. The passive function is to evaluate and process complaints, ethical issues or crime committed by members of Parliament. Factors that affect the performance is a code of ethics that has not been established, litigation procedures conflicts, the procedural issues of complaint, low cooperation of complaint, and the nature of solidarity among members of parliament. Board performance improvement strategy is based on the establishment of a code of ethics and litigation privilege Agency, meeting attendance evaluation, public courtroom, optimization of existing facilities in the working paper of Parliament. Board member attendance strategy evaluation is based on the evaluation of the Agency's internal honor, value filtering, the policy statement of honor Agency, penalties or rehabilitation.
\end{abstract}

Key words: strategy, regional representative, code of conduct, code of ethics

\begin{abstract}
Abstrak
Sesuai Pasal 154 ayat 2 UU 23 Tahun 2014 tata cara pelaksanaan Tugas dan wewenang DPRD diatur dalam tata tertib. Anggota DPRD Kabupaten/kota melaksanakan wewenang dan tugas lain sesuai peraturan perundang-undangan termasuk tentang kode etik. Alat kelengkapan DPRD dalam melaksanakan hak dan kewajiban berdasarkan Tata Tertib. Permasalahan yang dikaji dalam penulisan jurnal ini adalah: peranan Badan Kehormatan DPRD dalam penegakkan pelanggaran kode etik yang dilakukan anggota dewan, faktor Penghambat Kinerja Badan Kehormatan DPRD Kabupaten Pemalang dan strategi peningkatan kinerja badan kehormatan DPRD. Penelitian ini menggunakan pendekatan kualitatif dengan jenis penelitian yuridis sosiologis. Sumber data penelitian adalah data primer dan sekunder. Teknik pengambilan data: wawancara, observasi, dan studi pustaka. Hasil penelitian menunjukan bahwa dalam melaksanakan tugas dan wewenangnya Badan Kehormatan DPRD memiliki fungsi aktif dan
\end{abstract}


fungsi pasif. Fungsi aktif yaitu evaluasi setiap anggota dewan dalam rapat, mengawasi produk hukum yang dihasilkan DPRD, meninjau intensitas rapat yang dilakukan anggota DPRD. Fungsi pasif Badan Kehormatan yaitu mengevaluasi dan memproses aduan yang masuk, aduan dalam hal ini tentang permasalahan etik atau pidana yang dilakukan anggota DPRD. Faktor yang mempengaruhi kinerja Badan Kehormatan perekrutan anggota Badan Kehormatan, belum mengatur kode etik, terbenturnya tata beracara Badan Kehormatan, masalah prosedural pengaduan yang rumit, pengadu kurang bekerjasama, sifat solidaritas antar anggota DPRD. strategi peningkatan kinerja Badan kehormatan terealisasi: berdasarkan pembentukan kode etik dan tata beracara Badan Kehormatan, evaluasi kehadiran rapat, public hearing, optimalisasi sarana prasaran yang ada di DPRD. Strategi evaluasi kehadiran anggota dewan: evaluasi internal badan kehormatan, penyaringan nilai, pemanggilan anggota dewan, pernyataan anggota dewan, kebijakan badan kehormatan, pemberian sanksi atau rehabilitasi.

Kata kunci: strategi, Dewan Perwakilan Rakyat Daerah, tata tertib, kode etik

\section{Latar Belakang}

Salah satu keberhasilan era reformasi adalah amandemen UUD 1945. Walaupun masih memiliki kelemahan, UUD 1945 pasca amandemen telah meletakkan dasar-dasar kehidupan bernegara dan pembangunan hukum yang demokratis. Terlepas dari masih adanya pro dan kontra terhadap amandemen tersebut, UUD 1945 pasca amandemen harus ditempatkan sebagai hukum tertinggi yang sah berlaku karena dibuat oleh lembaga yang berwenang yaitu MPR melalui prosedur hukum yang sah pula.

Sebagai hukum tertinggi, di dalam UUD 1945 dimuat arah kebijakan hukum yang harus dijalankan sesuai dengan tujuan nasional yang hendak dicapai dan berdasarkan pada Pancasila yang termaktub dalam Pembukaan UUD 1945. Arah kebijakan hukum meliputi segala aspek kehidupan berbangsa, baik di bidang politik, ekonomi, maupun sosialbudaya. Sebagai prinsip utama politik hukum berdasarkan UUD 1945 adalah prinsip negara hukum dan supremasi konstitusi. ${ }^{1}$ Pasal 1 ayat (3) UUD 1945 menyatakan "Negara Indonesia adalah negara hukum".

Konsep negara hukum yang dulu dikesankan menganut konsep rechtsstaat dinetralkan menjadi negara hukum saja, tanpa label rechtsstaat. Konsep negara hukum yang dianut UUD 1945 diperoleh baik dari rechtsstaat maupun the rule of law, bahkan sistem hukum lainnya yang menyatu (integratif) dan implementasinya disesuaikan dengan tuntutan perkembangan. Konsep negara hukum Indonesia menerima prinsip kepastian hukum yang menjadi hal utama dalam konsep rechtsstaat, sekaligus juga menerima prinsip rasa keadilan dalam the rule of law.

Prinsip negara hukum juga dilakukan dengan penegasan supremasi konstitusi. Hal itu tertuang dalam Pasal 1 ayat (2) UUD 1945 yang menyatakan bahwa "kedaulatan berada di tangan rakyat dan dilaksanakan menurut ketentuan Undang-Undang Dasar. Dengan

1 Mahfud MD., “Capaian dan Proyeksi Hukum Indonesia”, Jurnal Hukum Vol. 16, No. 3, (Juli 2009): 291 - 310. 
demikian, pelaksanaan kekuasaan tertinggi dalam negara, yaitu kedaulatan, baik oleh lembaga negara maupun oleh warga negara harus dilakukan sesuai dengan ketentuan UUD 1945. Hal itu juga menegaskan kedudukan UUD 1945 sebagai hukum tertinggi yang mengatur pelaksanaan kedaulatan. Munck found it is important to consider the agencies' political decision-making political and social environment 'as well as the minimalist conceptions of democracy. ${ }^{2}$

Perspektif kedaulatan mendeskripsikan adanya regulasi tentang prinsip politik pada suatu wilayah. Karena pada dasarnya dalam kehidupan demokrasi kedudukan dan keberadaan hukum sangatlah penting. Hukum dibuat sebagai proses politik dan produk yang dihasilkannya patut menjadi pedoman untuk ditaati. Ketika apa yang disebut itu telah terbentuk dan dipatuhi sebagai aturan, salah satunya prinsip membentuk nilai, sikap dan perilaku maka saat itulah proses demokrasi telah mencapai tahap konsolidasi. In Democratic Theory Revisited, Satori (1987) argues that positive attitudes towards democracy often depend on leadership and performance. ${ }^{3}$

The emergence of contemporary democracies has to be seen in itshistorical and regional-cultural context. This includes the processes ofstate formation and nationbuilding, which often have pre-democraticor external origins. Sovereign states are the most important geopoliticalunits today, and they are the most influential actors in international politics. $^{4}$

Pemikiran demokrasi mengakibatkan jalannya roda pemerintahan harus sesuai dengan keinginan atau aspirasi rakyat, sesuai Dalam Undang-Undang Dasar Negara Republik Indonesia Tahun 1945 Pasal 1 ayat (2) secara tegas mengisyaratkan bahwa Indonesia mengakui kedaulatan rakyat. Dengan kata lain, pemerintah yang berkuasa harus mendapatkan legitimasi atau pengakuan dari rakyat. Dalam sisitem pemerintahan Indonesia, legitimasi rakyat tersebut diwakilkan kepada para wakil rakyat yang duduk di DPR RI pada tingkat pusat dan DPRD pada tingkat daerah.

Partai politik memiliki peranan yang sangat penting dalam setiap sistem demokrasi. Dalam suatu negara demokrasi, kedudukan dan peranan setiap lembaga negara haruslah sama-sama kuat dan ersifat saling mengendalikan dalam hubungan check and balance. Akan tetapi jika lembaga-lembaga negara tidak berfungsi dengan baik, kinerjanya tidak efektif, atau lemah wibawanya dalam menjalankan fungsinya masing-masing, maka hal tersebut dapat membuat partaipartai politik menjadi rakus. Menurut Miriam Budiarjo, partai politik memiliki 4 (empat) fungsi,antara lain sebagai saran komunikasi

2 Katharine Adeney and Paul Taggart, "Introduction: The Future of Democracy", Government and Opposition Vol. 50, Issue 3, (2015): 327.

3 Juliet Pietsch And Marshall Clark, "Critical Citizens: Attitudes towards Democracy in Indonesia and Malaysia", Japanese Journal of Political Science Vol. 16, Issue 2, (2015): 202.

4 Dirk Berg-Schlosser, "The Emergence of Democracy: Forces and Counter-forces", Government and Opposition Vol. 50, Issue 3, (Juli 2015): 337. 
politik, sosialisasi politik, rekruitmen politik, dan pengatur konflik. ${ }^{5}$

Fungsi ketiga partai politik yaitu rekruitmen politik merupakan sarana untuk menyeleksi kader-kader pemimpin negara pada jenjang-jenjang atau posisi tertentu. Kader-kader itu adayang dipilih secara langsung oleh rakyat, ada pula yang dipilh melalui cara tidak langsung, seperti oleh Dewan Perwakilan Rakyat, ataupun melalui cara-cara yang tidak langsung lainnya. Namun selain memiliki fungsi, partai politik juga memiliki kelemahan yaitu terkadang partai politik cenderung bersifat oligarkis.

Partai politik yang seharusnya mengutamakan kepentingan rakyat, namun pada kenyataannya cenderung lebih mengutamakan kepentingan partai politik itu sendiri.Untuk itu dalam partai politik, selain adanya anggaran dasar dan anggaran rumah tangga, maka diperlukan suatu kode etik positif yang dituangkan code of ethics yang dijamin tegaknya melalu dewan kehormatanyang efektif. Sesuai Pasal 366 UU Nomor 17 tahun 2014 ayat (1) secara rinci DPRD kabupaten Kota memilik tugas dan wewenang sebagai pelaksanakan wewenang dan tugas lain yang diatur dalam ketentuan peraturan perundangundangan.

Menurut tugas dan wewenangnya, DPRD memiliki hak interpelasi, hak angket, hak menyatakan pendapat. Namun selain tugas dan wewenang DPRD tersebut diatas, ada beberapa tugas dan wewenang DPRD lainnya yang diatur dalam peraturan perundangundangan. Dalam menjalankan tugas dan wewenangnya, DPRD dilengkapi dengan alat kelengkapan Dewan sesuai Pasal 375 ayat (1) f UU Nomor 17 tahun 2014, salah satunya adalah Badan Kehormatan. Harian Jateng memberitakan adanya anggota DPRD yang melakukan pencurian sehingga merugikan secara materil terhadap korbannya, pada saat pencurian tersebut korban ditangakap secara langsung oleh korban. Korban membawa tersangka beserta barang ke polisi. Hal diatas memberikan perlu adanya badan kehormatan untuk menyelesaikan perkara tersebut. Karena hal itu senada dengan substansi Pasal 124 UU Nomor 17 tahun 2014 ayat (1) b yaitu pelanggaran yang tidak memerlukan pengaduan adalah tertangkap tangan melakukan tindak pidana.

Badan Kehormatan yang menangani ranah etika tentu harus menindak lanjuti tentang pencurian yang dilakukan anggota dewan, karena hal sejalan dengan Pasal 119 ayat (2) UU nomor 17 tahun 2014 bahwa Mahkamah Kehormatan atau Badan Kehormatan bertujuan menjaga serta menegakkan kehormatan dan keluhuran martabat DPR sebagai lembaga perwakilan rakyat. Menurut ketua Badan Kehormatan bahwa penyelesaian perkasa tersebut sudah masuk ke Badan Kehormatan namun sampai sekarang belum ada jalan keluar untuk menyelesaikan perkara pencurian cincin batu akik yang dilakukan anggota DPRD Kabupaten Pemalang. 
Permasalahan dalam penelitian ini: kinerjanya. Karena anggota dewan merupakan Bagaimana peranan Badan Kehormatan DPRD dalam Penegakkan pelanggaran kode etik yang dilakukan anggota dewan; Faktor apa saja yang mempengaruhi kinerja Badan Kehormatan DPRD dalam penegakkan kode etik.Tujuan dari penelitian ini: Mengetahui peranan Badan Kehormatan DPRD dalam penegakkan pelanggaran kode etik yang dilakukan anggota dewan: Mengetahui faktorfaktor yang mempengaruhi kinerja Badan Kehormatan DPRD dalam menegakkan kode etik.

Sesuai Pasal 148 Undang-undang 23 Tahun 2014 tentang Pemerintah Daerah. DPRD kabupaten/kota merupakan lembaga perwakilan rakyatDaerah kabupaten/kota yang berkedudukan sebagai unsur penyelenggara Pemerintahan Daerah kabupaten/kota. Anggota DPRD kabupaten/kota adalah pejabat Daerah kabupaten/kota. Alat Kelengkapan DPRD Kabupaten/Kota sesuai pasal 163 Undang-Undang Nomor 23 Tahun 2014 tentang Pemerintah Daerah, alat kelengkapan DPRD kabupaten/kota salah satunya Badan Kehormatan yang bersifat tetap. Fungsi otonomi daerah sebagai bentuk kemandirian lembaga tentu menentukan kinerja dan tujuan atas keinginan sendiri, tanpa aturan yang memaksa. Badan kehormatan sebagai penjaga idealisme anggota dewan sangat diperlukan penilai dari kinerja eksekutif, The district governments - called kota/kabupaten - have become more autonomous, so that the heads of these district governments no longer report to the governor of the province. Instead, the district heads are responsible to the locally elected assembly (Dewan Perwakilan Rakyat Daerah, or DPRD) ${ }^{6}$

Etika berasal dari bahasa Yunani ethos, yang berarti kebiasaan. Sementara menurut Surahwardi K. Lubis, dalam istilah Latin, ethos atau ethikos selalu disebut dengan mos, sehingga dari perkataan tersebut lahirlah kata moralitas atau yang sering diistilahkan dengan perkataan moral. ${ }^{7}$ Dalam Kamus Besar Bahasa Indonesia dikatakan bahwa etika adalah ilmu tentang apa yang baik dan apa yang buruk dan tentang hak dan kewajiban moral (akhlak). Relevansi etika politik terletak pada kemampuannya untuk mengelola kekuatan itu dan mengatur kepentingan kepentingan kelompok dengan membangun institusiinstitusi politik yang lebih adil. Dalam hal ini, seorang anggota Badan Kehormatan idealnya menguasai Filsafat Politik, Filsafat Hukum dan Ilmu Hukum sebagai bentuk refleksi mendalam yang memungkinkan kehidupan politik mengungkap struktur-struktur, makna, dan nilainya secara etis. ${ }^{8}$

Demokrasi yang terkonkretisasikan

6 James Alm, R. H. Dkk, "Can Indonesia Decentralise Successfully? Plans Problems and Prospects”, Bulletin of Indonesian Economic Studies Vol. 37, Issue 1, (February 2001): 3.

7 Abdulkadir Muhammad, Etika Profesi Hukum, (Bandung: Citra Aditya Bakti, 2006), hlm. 13.

8 Marulak Pardede team, "Efektivitas Putusan Badan Kehormatan DPR/DPRD”, Badan Pembinaan Hukum Nasional Kementerian Hukum Dan HAM - RI, (2011): 45. 
dalam lembaga legislatif yang diimbangi dengan eksekutif dan yudikatif memiliki tiga komponen kualifikasi sebagai modus vivendi yang diharap dapat mendorong dan mengembangkan demokrasi yang sehat, yaitu kompetensi,konstituensi maupun integritas. ${ }^{9}$ Tiga komponen kualifikasi tersebut merupakan modus vivendi yang bersifat kumulatif bagi demokratisnya pelembagaan demokrasi secara hukum. Konstituensi memberikan legalitas kepada posisi politik seseorang dengan tanggung jawab yang harus diberikan kepada konstituensinya dapat diukur berdasarkan dedikasi.

Kompetensi memberikan efektivitas kepada posisi politik seseorang, dengan tanggung jawab yang harus diberikan kepada komitmen kerjanya dapat diukur berdasarkan prestasi. Sedangkan integritas memberikan legitimasi kepada seseorang dengan tanggung jawab berkenaan dengan komitmen terhadap nilai-nilai dan prinsipprinsip yang menjadi pedoman, oleh karena itu diukur berdasarkan kemampuan resistensi terhadap represi politik, komersialisasi dan tingkat otonomi berhadapan dengan deviasi politik.Hal ini berarti bahwa performance adalah sebuah tindakan yang dapat dilihat, diamati serta dimungkinkan untuk mencapai hal-hal yang diharapkan (tujuan). Kinerja juga dapat dikatakan kombinasi dari kemampuan, usaha dan kesempatan yang dapat dinilai dari hasil kerjanya yang diperoleh selama periode waktu tertentu.

Hal yang ditakutkan pada suatu lembaga jika tidak melakukan transparansi kinerja tentu akan memperoleh paksaan langsung dari konstituen, sesuai dengan teori Federico Traversa ${ }^{10}$ With respect to democracy itself, both the socioeconomic elite and the poor mayfind better security of their persons and their property under some dictatorships thanin a fully democratic regime, especially in unequal societies. It is very common thatthose who overthrow the democratic institutions justify their actions on the need torestore the order and security, especially with regard to the consequences ofdistributive conflicts. In this vein the dictators often justify the legitimacy thatderives from imposing a social order capable of generating material progress and theconditions to enjoy this achievement safely.

Jenis penelitian yang digunakan dalam penelitian hukum ini adalah penelitian Hukum sosiologis atau socio-legal research. Hukum sebagai gejala sosio empirik dapat dipelajari satu sisi sebagai independent variable yang menimbulkan efek-efek pada berbagai kehidupan sosial, dan di lain sisi, sebagai suatu resultante berbagai ragam kekuatan dalam proses sosial studi mengenai law in process. ${ }^{11}$ Tugas dan wewenang ini memberikan koreksi

9 Jimly Asshidiqie, Pergumulan Peran Pemerintah dan Parlemen Dalam Sejarah, (Jakarta: UI Press, 1996), hlm. 36 .

10 Federico Traversa, "Income And The Stability Of Democracy: Pushing Beyond The Borders Of Logic To Explain A Strong Correlation?”, Constitutional Political Economy Vol. 26, Issue 2, (June 2015): 131.

11 Bambang Sunggono, Metodologi Penelitian Hukum, (Jakarta: RajaGrafindo Persada, 2012), hlm. 101. 
atas kekurangan badan kehormatan dalam menyelesaikan pekerjaannya. Penelitian ini adalah penelitian hukum dengan pendekatan penelitian kualitatif hukum. Objek yang diteliti dan dipelajari adalah obyek penelitian yang utuh, sepanjang hal itu mengenai manusia. Dengan demikian, maka dengan menggunakan pendekatan kualitatif, seorang peneliti tidak boleh mengisolasikan individu atau organisasi kedalam variabel atau hipotesis, tetapi perlu memandangnya sebagai bagian dari sesuatu keutuhan. ${ }^{12}$

Peneliti dalam hal ini, ingin melihat secara jelas terhadap kinerja anggota Badan kehormatan DPRD Kabupaten Pemalang dalam menyelesaikan permasalahan yang masuk ke BKD, Data primer adalah data yang diperoleh dari sumbernya langsung maupun dari sumber pertama, yakni dengan mempelajari tingkah laku warga masyarakat setempat yakni dengan melalui penelitian. ${ }^{13}$ Sumber data primer diperoleh peneliti melalui wawancara terhadap informan. Pencatatan sumber data utama melalui wawancara merupakan hasil usaha gabungan dari kegiatan melihat, mendengar, dan bertanya yang dilakukan secara sadar, terarah, dan senantiasa bertujuan memperoleh informasi yang diperlukan.

\section{Pembahasan}

\section{A. Peranan Badan Kehormatan} DPRD dalam Penegakan Kode Etik DPRD Kabupaten Pemalang

Substansial peranan merupakan aspek dinamis kedudukan (status). Status merupakan sekumpulan hak dan kewajiban sesuai dengan kedudukannya, maka peranan dapat di maksud fungsi. Teori peranan dihubungkan dengan pola law enforcement, pola penegakkan hukum secara penuh sesuai tata peraturan perundang-undangan. ${ }^{14}$ Badan Kehormatan (BK) merupakan alat kelengkapan DPRD Kabupaten Pemalang yang keberadaannya penting untuk menegakan kode etik anggota dewan.

Timbulnya kritik terhadap suatu alat kelembagaannegaraataupundaerahdidasarkan pada kualitas manusia sesuai pandangan pietsch, ${ }^{15}$ Liddle and Mujani'squantitative analysis of post-election surveys since 1998 found that critical citizens in Indonesia value democracy but are critical of its performance. They find that citizens with a higher socioeconomic background tend to be more critical of democratic performance. The higher the level of education, the more negative is his or her evaluation of democratic performance.

Fungsi Badan Kehormatan dalam penegakan kode etik sangatlah penting

12 Lexy J. Moleong, Metodologi Penelitian Kualitatif, (Bandung: Rosda Karya, 2010), hlm. 4.

13 Soerjono Soekanto, Pengantar Penelitian Hukum, (Jakarta: UI Press, 2005), hlm. 12.

14 Soerjono Soekanto, Sosiologi Suatu Pengantar, (Jakarta: Rajawali Pers, 2009), hlm. 212-213.

15 Lily Zubaidah Rahim dan Juliet Pietsch "Introduction: States, Critical Citizens, and the Challenge of Democratization in Southeast Asia", Japanese Journal of Political Science Vol. 16, Issue 2, Cambridge University Press, (2015): 141. 
guna menjaga etika dan moral Anggota DPRD sebagai wakil rakyat. Dalam hal ini implementasi fungsi Badan Kehormatan diartikan dengan bagaimana pelaksanaan atau penerapan fungsi Badan Kehormatan dalam penegakan kode etik di DPRD Kabupaten Pemalang periode 2014-2019. Badan Kehormatan bertugas untuk melaksanakan pengawasan dan kontrol terhadap DPRD.

Pengawasan dan kontrol dalam hal ini adalah pengawasandan kontrol internal terhadap DPRD. Anggota DPRD merupakan para wakil rakyat yang dipilih melalui pemilihan umum. Tentang etika, pada dasarnya merupakan tentang etis dan tidaknya suatu tindakan tertentu terkait dengan fungsi, tugas, wewenang, dan tanggungjawab serta kedudukan seseorang sebagai anggota DPRD. Dalam profesinya sebagai anggota DPRD, maka disini perlu adanya kode etik profesi untuk memberikan batasan guna menjaga profesionalitas anggota DPRD agar tidak terjadi penyimpangan. ${ }^{16}$

Kode etik profesi tersebut terwujud dalam tata tertib dan kode etik DPRD. Dalam menjalankan tugas dan wewenangnya, Badan Kehormatan memiliki pedoman beracara tersendiri. Tata tertib sebagai aturan normatif di DPRD, kode etik sebagai batas-batas aturan main anggota dewan dan pedoman beracara Badan Kehormatan merupakan aturan main Badan Kehormatan sendiri. Kode Etik DPRD merupakan keberlanjutan dari Tata Tertib
DPRD. Pada dasarnya Badan Kehormatan mempunyai 2 fungsi, yaitu fungsi aktif dan fungsi pasif.

Fungsi aktif Badan Kehormatan yaitu dengan mengevaluasi setiap absensi anggota dewan dalam rapat-rapat, mengawasi produk hukum yang dihasilkan DPRD, dan meninjau intensitas rapat yang dilakukan oleh DPRD. Badan Kehormatan selalu mengevaluasi absensi anggota dewan setiap 3 (tiga) bulan sekali. Dalam kurun waktu 2014-2019, terdapat beberapa anggota dewan yang kerap mangkir dari rapat. Rapat tersebut tidak hanya pada rapat paripurna yang berskala besar, namun juga pada rapat-rapat lain seperti rapat komisi maupun rapat fraksi yang berskala kecil.

Menindaklanjuti hal itu, Badan Kehormatan telah memberikan teguran lisan untuk anggota dewan tersebut melalui fraksi tempat anggota dewan tersebut berasal. Selain mengevalusi absensi, Badan Kehormatan juga mengevaluasi intensitas rapat yang dilakukan oleh anggota dewan. Ini penting, karena ketika intensitas rapat menurun, maka produk hukum yang dihasilkan bisa jadi juga menurun. Dalam hal ini Badan Kehormatan telah memberi teguran lisan dan peringatan untuk komisi, fraksi, dan rapat-rapat yang lain yang dinilai intensitas rapatnya menurun.

Fungsi pasif Badan Kehormatan yaitu tindakan Badan Kehormatan terhadap pengaduan yang masuk. Pengaduan dalam

16 Murhani, Suriansyah, Aspek Hukum Pengawasan Pemerintah Daerah, (Yogyakarta: Laksbang Mediatama, 2008), hlm. 69. 
hal ini adalah pemberitahuan tertulis disertai bukti awal terhadap suatu tindakan dan/atau peristiwa yang patut diduga sebagai suatu pelanggaran Tata Tertib dan Kode Etik yang dilakukan oleh Anggota Dewan. Badan Kehormatan secara internal membahas suratsurat pengaduan yang masuk setiap 1(satu) bulan sekali. Fungsi aktif dan fungsi pasif mendorong kemajuan dari Badan Kehormatan ini, sepeti penelitian Martin Paldam ${ }^{17}$ The key observation is that all bureaucrats have a joint interest in the growth of their bureau. It gives jobs, perks and appointments.

Pengaduan tersebut dapat diajukan oleh masyarakat ataupun lembaga. Sepanjang tahun 2014-2019, memang ada beberapa aduan yang masuk dari masyarakat. Pengaduan-pengaduan yang masuk tersebut, tidak semua ditindaklanjuti oleh Badan Kehormatan karena pengaduan tidak sesuai prosedur yang berlaku. Pada periode tersebut Badan Kehormatan telah menindak 1 (satu) pengaduan yang telah sesuai prosedur, yaitu kasus pencurian tempat batu akik yang dilakukan oleh salah satu anggota dewan.

Selain tindakan Badan Kehormatan yang tersebut diatas, Badan Kehormatan juga selalu berperan aktif dalam memberikan himbauan kepada anggota-anggota dewan agar tidak melakukan pelanggaran atau melakukan perilaku-perilaku menyimpang yang dapat merusak citra dewan. Untuk anggota yang tidak hadir 1 (satu) kali tanpa keterangan, Badan Kehormatan juga langsung memberikan peringatan agar hal tersebut tidak terulang.

Pada periode 2014-2019, Badan Kehormatan DPRD Kabupaten Pemalang belum pernah sampai memberikan sanksi tertulis maupun sanksi memberhentikan. Sejauh ini Badan Kehormatan lebih sering memberikan sanksi lisan, karena Badan Kehormatan mengutamakan sifat kekeluargaan. Namun justru hal tersebut membuat Badan Kehormatan terlihat kurang berani dalam menindak suatu pelanggaran. Jika dibanding dengan periode sekarang, kasus yang ada di DPRD Kabupaten Pemalang memang lebih banyak pada periode sebelumnya.

Pada periode ini, anggota Badan Kehormatan juga kurang aktif dalam memberikan himbauan, peringatan, maupun teguran. karena mengutamakan rasa kekeluargaan maka Badan Kehormatan jadi terlihat pasif. Dari penelitian yang dilakukan di Badan Kehormatan DPRD Kabupaten Pemalang, peneliti menyimpulkan bahwa peran Badan Kehormatan dalam penegakan kode etik DPRD belum maksimal. Pada dasarnya fungsi Badan Kehormatan belum dijalankan dengan baik.

Hal tersebut karena selama ini apa yang dilakukan Badan Kehormatan dalam menegakankode etik masih belum memberikan efek jera terhadap anggota dewan yang 
melanggar kode etik. Pembentukan Badan Kehormatan di parlemen pada dasarnya sudah tepat, namun pelaksanaannya masih belum cukup kuat untuk benar-benar menegakan Kode Etik yang ada. Sebagai lembaga pengawas internal DPRD yang bertugas menegakan tata tertib dan kode etik DPRD, Badan Kehormatan harus tegas agar tata tertib dan kode etik benar-benar dapat ditegakan. Badan Kehormatan dalam bertindak harus sesuai norma dan prinsip hukum global sesuai pandangan Leonard ${ }^{18}$ that the state act in accordance with normsemerging patterns of global governance and in fact, become agents of internationalPeople's desire to improve the problem-which collectively becoming violationcore crimes of humanitarian law. This shows a clear relationship between the principleuniversal jurisdiction and global governance.

\section{B. Faktor Penghambat Kinerja Badan Kehormatan DPRD Kabupaten Pemalang}

Setiap organisasi atau lembaga tentunya mempunyai faktor penghambat dalam menjalankan tugasnya. Tentunya Badan Kehormatan sebagai alat kelengkapan yang diharapkan dapat menegakkan aturan-aturan yang ada juga menemukan penghambat dalam menjalankan tugasnya. Berikut ini beberapa faktor penghambat kinerja Badan Kehormatan DPRD Kabupaten Pemalang dalam menjalankan tugasnya.

Perekrutan anggota Badan Kehormatan sebagai kendala pertama, perekrutan dilaksanakan pada awal periode DPRD disahkan melalui keputusan DPRD untuk masa kerja 2 setengah tahun. Aturan khusus mengenai recruitment anggota Badan Kehormatan Dalam Pasal 56 ayat (5) PP Nomor 16 tahun 2010 tentang Pedoman Penyusunan Peraturan Dewan Perwakilan Rakyat Daerah tentang Tata Tertib. Dewan Perwakilan Rakyat Daerah disebutkan bahwa anggota Badan Kehormatan dipilih dan ditetapkan dalam rapat paripurna DPRD.

Anggota Badan Kehormatan diusulkan berdasarkan dari masing-masing fraksi. Dalam hal ini masing-masing fraksi berhak mengusulkan satu orang calon anggota Badan Kehormatan. Dalam aturan tersebut tidak terdapat aturan yang jelas mengenai recruitment calon anggota Badan Kehormatan. Tidak ada aturan mengenai syarat khusus yang harus dipenuhi untuk menjadi calon anggota Badan Kehormatan yang diusulkan oleh fraksi.

Hal ini tentu saja dapat menjadi faktor penghambat Badan Kehormatan dalam menjalankan tugasnya. Karena terdapat fraksi yang justru memasukkan anggotanya yang bermasalah untuk menjadi anggota Badan Kehormatan guna untuk memperbaiki diri anggota tersebut. Badan Kehormatan bukan merupakan tempat untuk sarana 
memperbaiki diri, namun Badan Kehormatan dibentuk untuk menegakan tata tertib dan kode etik yang mana seharusnya orang-orang yang dimasukkan sebagai anggota Badan Kehormatan adalah benar-benar orang yang berkualitas dan tidak bermasalah. Anggota Badan Kehormatan yang sebagian banyak laki-laki mengaburkan prinsip the 'crisis of democracy' may provide opportunities to further enhance women's participation, as the demands of those favouring greater gender equality and those looking for solutions to the 'crisis' appear to coincide. ${ }^{19}$

Tata Tertib DPRD hanya bersifat umum sebagai kendala yang kedua. Tata tertib disahkan pada awal periode DPRD, tata tertib bersifat mengatur pelaksanaan, wewenang dan fungsi tiap alat kelengkapan dewan. Dalam tata tertib dijelaskan tentang pembentukan kode etik sebagai batasan kerja dan etika anggota DPRD. Kode etik merupakan suatu aturan-aturan tertulis yang diharapkan dapat membimbing anggota dewan agar tidak terjadinya kesewenang-wenangan kekuasaan.

Kode etik yang aktual belum dibentuk atau beridiri sendiri sehingga anggota dewan yang "nakal" tidak terkena sanksi. Pada Pasal 117 ayat (2) Peraturan Dewan Perwakilan Rakyat Daerah Kabupaten Pemalang Nomor 1 Tahun 2014 tentang Tata Tertib. dalam pasal tersebut dikatan bahwa kode etik diatur tersendiri dengan peraturan DPRD, hal ini jelas perlu dilakukan pembentukan kode etik dan dilanjutkan sidang paripurna oleh DPRD untuk membentuk kode etik. Yang tertuang dalam pasal 117 ayat (1) juga jelas kode etik dibentuk untuk menjaga martabat, kehormatan, citra, dan kredibiltas DPRD yang berisi norma yang wajib dipatuhi oleh setiap anggota DPRD, tetapi dalam realitasnya kode etik belum dibentuk sama sekali selama periode 2014-2019. Hubungan aturan yang digunakan disesuaikan dengan karakter subyek yang mengoperasikan lembaga pemerintahan sesuai dengan pernyataan The essential requirements of the operational coupling of the legal system to core operational structure of the target agent community is that there are enough individual agencies and organizations in the community unit capable agent perform the behavior and interaction required by the judicial organ of the law system, so that they are agents of individuals and organizational units can carry out legal functions performed by the organs of law. ${ }^{20}$

Pedoman TataBeracara Badan Kehormatan sebagai kendala. Karena tata beracara Badak Kehormatan DPRD Kabupaten Pemalang belum terbentuk. Setiap menyelesaikan pengaduan dari masyarakat atau anggota DPRD, Badan kehormatan menggunakan tata beracara yang didasarkan dari peraturan DPRD tentang tata beracara sesuai Peraturan Menteri Dalam Negeri Republik Indonesia Nomor 1 Tahun 2014 Pasal 47 Ayat (2) C.

19 Georgina Waylen, "Engendering the 'Crisis of Democracy': Institutions, Representation and Participation", Government and Opposition Vol. 50, Issue 3, (July 2015): 495.

20 Antonio Carlos Rocha Costa, "Situated legal systems and their operational semantics", Journal Artificial Intelligence and Law Vol. 23, Issue 1, (March 2015): 51. 
Badan Kehormatan dapat dituntut ketika tidak mengikuti prosedural beracara yang ada. Seperti pengaduan, ada pengaduan yang masuk ke Badan Kehormatan namun tidak diproses karena pengaduan tersebut tidak lengkap. Pengaduan yang masuk ke Badan Kehormatan tanpa adanya identitas dari pengadu, maka pengaduan tersebut hanya dijadikan catatan oleh Badan Kehormatan.

Badan Kehormatan terbatasi oleh aturan yang malah terkadang membuat Badan Kehormatan sulit untuk menindak anggota dewan yang benar-benar melanggar tata tertib dikarenakan belum terbentuk tata beracara BK. Seharusnya pedoman tata beracara Badan Kehormatan dibuat agar semakin mempertegas tata tertib DPRD. Untuk saat ini Badan Kehormatan memang masih mengacu pada pedoman Tata Beracara DPR RI. Namun seharusnya Badan Kehormatan dapat lebih cepat dalam merumuskan Pedoman Tata Beracara agar Badan Kehormatan terlihat lebih Mandiri. Tata aturan yang tidak kondusif memaksakan kerancuan dalam menjalankan tugas dan fungsi suatu lembaga pemerintahan, The broken link between legal interpretation and legislative technique seems to be the root of the trouble. If the legislator takes too little interest in the accuracy and consistency of law, then there is no unity of legal order and no clear rule. ${ }^{21}$

Masalah prosedural pengaduan yang rumit sebagai kendala. Badan Kehormatan dapat menindak suatu pelanggaran karena ada pengaduan dari pimpinan DPRD, anggota DPRD, dan/atau masyarakat. Tata cara pengaduan yang seharusnya diatur dalam kode etik dan pedoman tata beracara Badan Kehormatan, namun belum dibentuk sehingga tidak ada kepastian hukum dalam proses kerja BK. Pengaduan harus memuat identitas pengadu, identitas teradu, dan uraian singkat mengenai pelanggaran yang dilakukan. Hal ini dapat menghambat Badan Kehormatan menindaklanjuti pengaduan ketika muatan dalam pengaduan tersebut tidak lengkap.

Seringkali ada pengaduan yang masuk ke Badan Kehormatan, tetapi kadang identitas pengadu maupun teradu tidak lengkap dan jenis pelanggaran yang diadukan tidak jelas. Pengaduan yang tidak sesuai ketentuan hanya akan dianggap sebagai surat kaleng dan hanya menjadi catatan Badan Kehormatan. Masyarakat menjadi enggan untuk mengajukan pengaduan karena aturan mengajukan pengaduan yang dinilai rumit. Sehingga pada periode 2009-2014 dan 20142019 tidak banyak pengaduan yang masuk ke Badan Kehormatan.

Pengadu kurang bekerjasama sebagai kendala kelima. Proses nonprovit seringkali sebagai masalah dalam jalannya proses kinerja lembaga pemerintahan seperti pandangan weingast Thisrequire creating the right incentives for those who depend on a credible commitmentfor certain elements of

21 Doris Liebwald, “On Transparent Law, Good Legislation And Accessibility To Legal Information: Towards An Integrated Legal Information System”, Artificial Intelligence and Law Vol. 23, Issue 3, (September 2015): 308. 
government organizations-in particular the commitment toupholds some degree of local autonomy combined with the right incentives. More specifically, the literature identifies two conditions for the implementationgrowth enhancing policies at the sub-national level: a realistic promotion opportunitiesfor local politicians based on their performance, and the allocation of the remaining budgetrevenues to the local budget. ${ }^{22}$

Pihak pengadu yang sulit dihubungi juga menjadi hambatan atau kendala Badan Kehormatan untuk menjalankan tugasnya. Hal ini karena beberapa pengaduan yang masuk, seringkali pengadu sulit dihubungi. Ketika pengaduan yang masuk sudah sesuai prosedur, Badan Kehormatan dalam menindaklanjutinya perlu keterangan langsung dari pengadu.

Ketika pengadu sulit dihubungi maka Badan Kehormatan menjadi terhambat dalam menindaklanjutinya ketika tidak ada keterangan lebih lanjut dari pengadu, karena mau tidak mau Badan Kehormatan harus mengikuti pedoman tata beracara yang ada. Jika tidak sesuai pedoman dan prosedur yang ada ketika menindak lanjuti pengaduan, maka Badan Kehormatan dapat dituntut.

Sifat solidaritas antar anggota DPRD sebagai kendala keenam dalam hambatan pelaksanaan tugas Badan Kehrmatan.Prinsip solidaritas sesama anggota dewan ternyata berakibat fatal, In other words, crime is a fault shared by members of the government that a crime has been committed-they shared the error to the extent that they true of all members of the government-and, thus, should be handled by society itself. ${ }^{23}$ Unsur politis menjadi hambatan yang sangat mempengaruhi kinerja Badan Kehormatan. Anggota Badan Kehormatan juga merupakan anggota dewan yang terdiri dari masing-masing fraksi yang ada di DPRD. Hal ini sangat berpengaruh pada Badan Kehormatan ketika akan menegakan aturan yang ada. Disatu sisi Badan Kehormatan merupakan alat kelengkapan yang memang dibuat untuk menegakan etika, namun disisi lain Badan Kehormatan juga merupakan anggota dewan yang berasal dari fraksi-fraksi.

Dalam suatu kasus Badan Kehormatan sulit menegakan kode etik yang berlaku karena pelanggaran dilakukan oleh ketua dalam fraksinya sendiri. Hal itu karena ketika Badan Kehormatan hendak menegakan kode etik yang berlaku, namun terbentur oleh posisinya di fraksi tersebut yang dapat terancam karena pelanggar tersebut adalah ketuanya sendiri. Selain itu Badan Kehormatan juga sulit bertindak ketika pelanggaran dilakukan oleh teman dekat sendiri yang sesama anggota dewan. Ada sifat solidaritas dan proteksi yang diberikan karena kedekatan psikologis. Sistem lobi membuat prosedural penyelesaian permasalahan BK sulit diselesaikan sesuai

22 Barbara Krug dan Alexander Libman, "Commitment To Local Autonomy In Non-Democracies Russia And China Compared”, Constitutional Political Economy Vol. 26, Issue 3, (June, 2015): 224.

23 Alfonso Donoso, "Commentaries on Criminal Law Conversations", Criminal Law and Philosophy Vol. 9, Issue 
gambaran While deep-rooted in the political economy literature on the interplay of economic and political agents within given institutional arrangements, the present analysis also relates to other lines of research. A natural complement is arguably the theory of rent-seeking focusing on tailoring public policies to special interests or personal advantages. According to this approach, the role of lobbying in the political arena has been investigated by means of reduced-form contest models aimed at capturing the deep Connecti ons and interdependencies between public decision-making and external influence activities which naturally arise in modern representative democracies. ${ }^{24}$

\section{Strategi Meningkatkan Kinerja Badan Kehormatan DPRD Kabupaten Pemalang}

Fenomena sosial tentang kerja suatu lembaga dibentuk karena perjanjian antar dua atau lebih subyek hal ini dapat dilihat dari Many social phenomena rest upon transactions that extend over a significant time interval: indeed, it is impossible to imagine a society in which such transactions did not occur all the time. Such transactions would be impossible if social actors could not convince one another that they would honor their action promises. ${ }^{25}$ Transaksi sosial yang berdasarkan lembaga negara harus berdasarkan dasar hukum yang jelas. Maka perlu adanya strategi peningkatan kinerja Badan Kehormatan untuk mengoptimalkan fungsi dan wewenangnya sebagai penjaga warwah dan martabat DPRD, Badan Kehormatan DPRD Kabupaten Pemalang memiliki beberapa hal yang harus ditempuh. Hal pertama yang harus dilaksanakan Badan Kehormatan adalah membentuk kode etik dalam aturan tersendiri di DPRD sebagai aturan materiil, sebagai tata kerja badan kehormatan dan tolak ukur penentuan sanksi kepada anggota dewan yang melakukan pelanggaran etika ataupun pidana. Sehingga didapat kriteria sanksi dari yang ringan sampai yang berat.

Evaluasi kehadiran rapat dan kunjungan kerja setiap anggota dewan yang perlu dilaksanakan, karena dalam periode Badan Kehormatan saat ini belum terlaksanakan hal itu dan harus dimasukan kedalam kode etik. Seperti pendapat Pak Irwanto bahwa belum ada evaluasi pada daftar kehadiran anggota DPRD Kabupaten Pemalang pada periode 2014-2019. Badan Kehormatan juga mendapat bantuan dari sekretariat DPRD dalam pengumpulan absensi anggota dewan tentu hal ini sangan membantu Badan Kehormatan. Namun kurang transparan dalam pembahasan rekap kehadiran anggota DPRD dalam setiap rapat atau kunjungan kerja memberikan pandangan kurang produktifnya anggota DPRD dalam melakukan funginya

24 Marco M. Sorge, "Lobbying (Strategically Appointed) Bureaucrats”, Constitutional Political Economy Vol. 26, Issue 2, (June 2015): 174.

25 Alan D. Morrison and William J. Wilhelm Jr,"Trust, Reputation, And Law: The Evolution Of Commitment In Investment Banking”, Journal of Legal Analysis Vol. 7, Issue 2, (2015): 368. 
yaitu legislasi, pengawasan, dan anggran.

Pembentukan tata beracara sebagai aturan formil dalam mereformasi kinerja Badan Kehormatan agar seperti Mahkamah Kehormatan Dewan yang ada di DPR Republik Indonesia, sehingga tercipta sistem peradilan etik diranah legislatif. Hal ini sejalan juga dengan Undang-Undang Nomor 17 tahun 2014 tentang MD3, dan Peraturan DPR RI Nomor 22 Tahun 2015 Tata beracara Mahkamah Kehormatan Dewan, agar tercipta hirarki pemerintahan yang bersinergi dan integralistik.

Aspirasi dan pandangan masyarakat sebagai pacuan utama untuk mereformasi kinerja Badan kehormatan, hal ini butuhkan wadah yang bisa menampung pandangan dan aspirasi masyarakat dengan membentuk suatu website atau situs dalam internet, bisa dengan media sosial. Hal ini tentunya bertujuan aktualisasi dalam memberikan informasi kepada masyarakat tentang kinerja Badan kehormatan tiap dalam evaluasi rekap kehadiran maupun penyelesaiaan aduan yang masuk ke Badan Kehormatan DPRD Kabupaten Pemalang. Substansi moralitas digunakan sebagai landasan dasar dalam rapat dan pembahasan tugas $\mathrm{BK}$ sesuai teori Morality means a set of rules that govern human living together in society in the basis of mutual respect. ${ }^{26}$

Public Hearing, evaluasi kinerja secara langsung dipertanggung jawabkan kepada masyarakat dengan melakukan audiensi setiap tiga (3) bulan sekali. Untuk memperoleh kritik dan saran dari masyarakat secara langsung atas tindakan dan kerja tiap anggota DPRD Kabupaten Pemalang. Badan kehormatan juga memaparkan hal apa saja yang telah dilaksanakan dan diselesaiakan. Prinsip demokrasi sesungguhnya adalah bertanggung jawab langsung kepada masyarakat sebagai leader of constitution. Mengoptimalkan sarana dan prasarana yang tersedia agar Badan Kehormatan dapat memaksimalkan penegakan tata tertib dan DPRD. Badan Kehormatan dapat memanfaatkan CCTV (Closed-circuit television) yang telah terpasang di setiap sudut ruangan di DPRD Kabupaten Pemalang untuk mengawasi tingkah laku anggota dewan.

Penetapan kebijakan yang dilakukan dalam menyelesaikan aduan yang masuk ke Badan Kehormatan menggunakan alur aduan setelah itu proses dan akhirnya keputusan sesuai tata tertib nomor 1 DPRD Kabupaten Pemalang. Berawal dari aduan yang disampaikan dalam laporan tertulis yang dilampirkan dengan syarat pelaporan dugaan pelanggaran etika. Proses tindak lanjut aduan dilakukan melalui musyawarah internal antar anggota Badan Kehormatan. Keputusan merupakan hasil musyawarah bersama dari anggota Badan Kehormatan sesuai dengan keputusan pengadilan jika berkenaan dengan pidana, untuk aturan pelanggaran yang bersinggungan dengan hal tentang perilaku hanya bersifat teguran atau sanksi lisan, tidak didefinisikan

26 Paul Tiedemann, "Is There a Human Right to Freedom of Religion?", Human Rights Review Vol. 16, Issue 2, (June 2015): 89. 
sesuai pelanggaran yang dilakukan. Badan Kehormatan yang kedudukannya sebagai alat kelengkapan dewan, dalam menentukan diproses atau tidak aduan yang masuk sesuai arahan dari pimpinan dewan, sehingga independensi Badan Kehormatan dalam membuat keputusan masih diragukan.

Strategi dalam pembuatan keputusan badan kehormatan dilaksanakan dengan aduan, proses, keputusan, sanksi/rehabilitasi. Proses beracara dilakukan dengan tata beracara tersendiri. Dan diatur kedalam kode etik sebagai aturan yang digunakan dalam beracara dan memberikan putusan. Berkenaan dengan sanksi yang diberikan setelah putusan disesuaikan dengan pelanggaran yang dilakukan yaitu ringan, sedang ataupun berat, lebih detailnya diatur kedalam peraturan DPRD tentang Kode Etik. Pemberian keputusan yang dilakukan Badan kehormatan juga sesaui norma yang ada atas dasar pertimbangannya sendiri, tanpa ada intervensi secara politik ataupun lembaga. Sehingga integritas DPRD dan khususnya Badan Kehormatan lebih terjaga dengan penilaian citra yang baik. Karena pada dasarnya dalam Peraturan Pemerintah Nomor 16 Tahun 2010 Pasal 89 ayat (2) ketentuan mengenai kode

\section{Bagan 1. Alur Evaluasi Kehadiran Anggota Dewan}

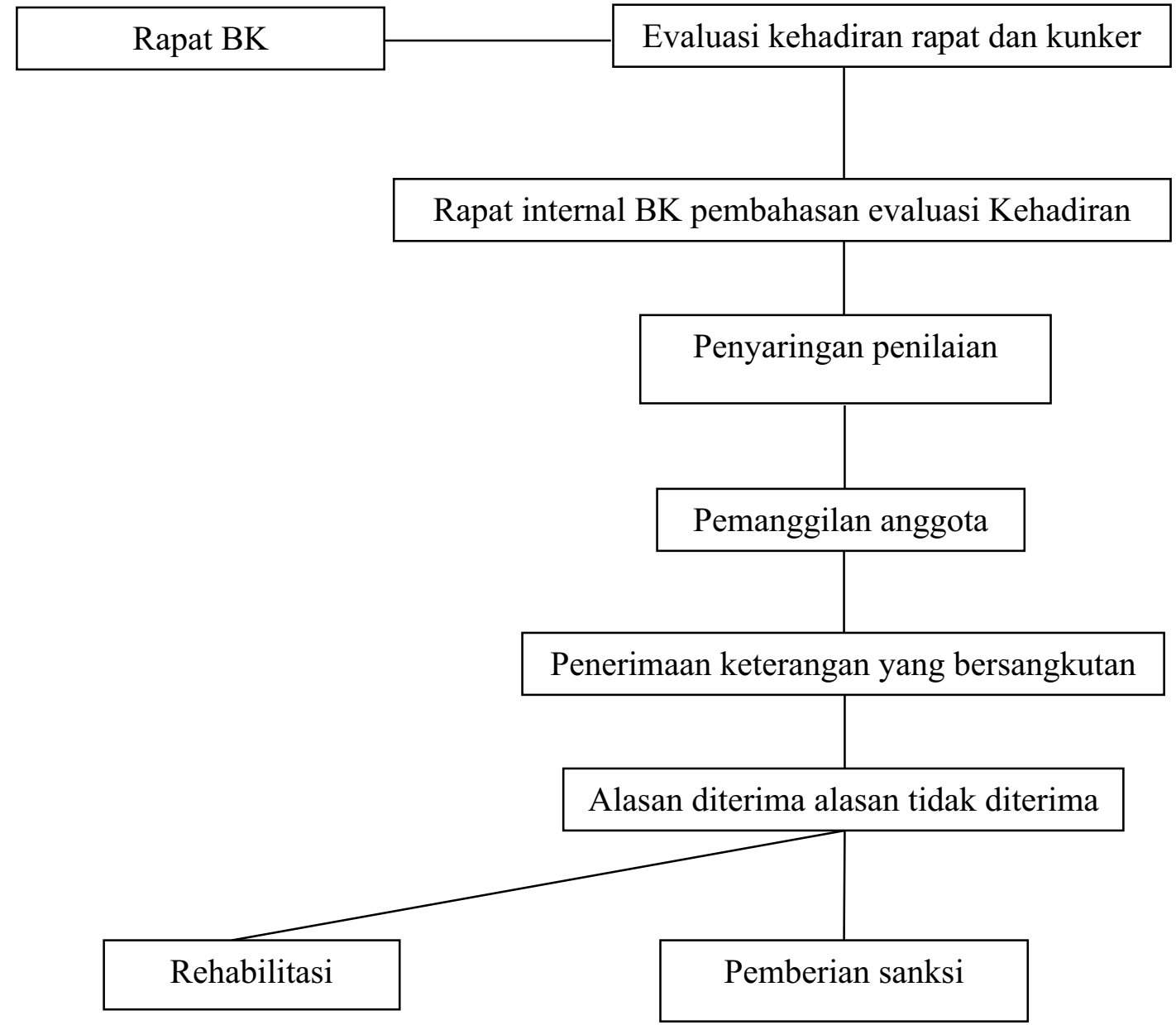

Sumber: Peraturan Pemerintah Nomor 16 Tahun 2010 tentang Pedoman Penyusunan Peraturan DPRD 
etik diatur tersendiri dalan peraturan DPRD.

Salah satu fungsi aktif Badan Kehormatan adalah evaluasi kehadiran anggota dewan dalam setiap rapat dan kunjungan kerja. Tetapi realitas dilapangan bahwa evaluasi rutin yang harus dilaksanakan badan kehrmatan tidak pernah terlaksana. Untuk itu perlu dirancang strategi dalam pelaksanaan evaluasi kehadiran anggota dewan diawali dengan rapat Badan Kehormatan.

Rapat Badan Kehormatan merupakan kegiatan rutin Badan Kehormatan tiap (1) satu bulan sekali untuk meninjau evaluasi kerja dan masukan dari masyarakat. Musyawarah dengan aparatur hukum apabila ada anggota dewan yang bermasalah dengan kasus hukum. Mengundang tenaga Ahli untuk memberikan masukan terkait anggota dewan yang bermasalah dengan hukum. Sesuai dengan masukan dari James Green Voters may gain pride or respect from voting intelligently, putting their values into practice, and taking an active role in determining the rules of their society. ${ }^{27}$

Evaluasi Kehadiran rapat dan kunker kehadiran anggota Dewan dalam setiap rapat dan kunjungan kerja sebagai kewajiban atas beban dan tanggungjawab sebagai anggota dewan. Anggota Dewan berkewajiban menyerap dan menerima aspirasi masyarakat sesuai Pasal 373 UU No 17 Tahun 2014. Rapat Internal pembahasan evaluasi kehadiran pembahasna evaluasi dilaksanakan untuk menggambarkan keseriusan Badan kehormatan dalam menjalankan tugas dan wewenangnya. Komitmen Badan Kehormatan kepada konstituen merupakan dasar dalam bertindak. Jumlah rapat dan kunker yang banyak membutuhkan evaluasi yang benarbenar teliti dengan bantuan tenaga ahli. Kebebasan dalam memberikan penilaian terhadap anggota dewan ditentukam tanpa paksaan.

Penyaringan penilaian kehadiran berupa presentase dengan kategori baik, cukup, atau buruk. Penilaian berdasarkan jumlah kehadiran dan ketidak hadiran. Sesuai penjelasan ketua Badan Kehormatan DPRD Kabupaten Pemalang. Anggota DPRD yang 6 kali berturut-turut dan dilepas dari keanggotaan. menurut peneliti kategori Baik dengan presentase $100 \%$ kehadiran, kategori cukup 1 kali tidak hadir rapat atau kunker dengan alasan yang rasional dan berbukti. Kategori buruk dengan ketidak hadiran anggota dewan dalam rapat atau kunker sebanyak 2 kali atau lebih tanpa alasan. Pandangan viner diambil dari hayek bahwa Hayek understands liberty in the classical sense as absence of coercion; it is notan end in itself but just a means towards other ends. ${ }^{28}$

Pemanggilan anggota pemanggilan anggota dewan yang menerima penilaian dengan Kategori cukup dan buruk.

27 James Green-Armytage, "Direct Voting And Proxy Voting”, Constitutional Political Economy Vol. 26, Issue 2, (June 2015): 210.

28 Athanassios Pitsoulis and Steffen W. Groß, "The Other Side Of The Argument": Isaiah Berlin Versus F. A. Von Hayek on Liberty, Public Policies and The Market", Constitutional Political Economy Vol. 26, Issue 4, (December 2015): 15 . 
Pemanggilan dilakukan untuk dimintai keterangan atas ketidak hadiran dalam rapat atau kunjungan kerja. Pemanggilan anggota dewan melalui surat resmi yang dikeluarkan ketua Badan Kehormatan. Penerimaan keterangan yang bersangkutan setelah dilakukan pemanggilan anggota dewan yang memiliki kategori cukup dan buruk. Maka Badan kehormatan bisa meminta keterangan secara langsung kepada anggota dewan yang menerima penilaian dengan kategori cukup ataupun buruk.

Alasan diterima atau tidak diterima Badan Kehormatan dengan wewenangnya dapat memberikan penilaian atas alasan yang diberikan oleh anggota dewan yang berkategori cukup atau buruk. Alasan dapat diterima jika anggota dewan memberikan keterangan dengan bukti kuat dan keterangan dari ahli. Alasan tidak diterima jika anggota dewan tidak bisa membuktikan keterangan yang diberikan kepada Badan Kehormatan. The agent may display some form of akrasia, but weakness of the will is not an excusing ormitigating condition, but a straight moral failure. $^{29}$

Rehabilitasi merupakan penilaian kembali yang dilakukan oleh Badan Kehormatan. Anggota Dewan memberikan keterangan yang dapat diterima oleh Badan Kehormatan. Maka Badan Kehormatan memberikan surat penilaian yang kedua kepada anggota Dewan yang sebelumnya mendapatkan kategori cukup. Badan kehormatan memberikan penilaian kembali menjadi penilaian Baik.

Sanksi diberikan kepada anggota dewan dengan kategori buruk dan tidak bisa memberikan alasan yang dapat diterima oleh Badan Kehormatan. Pemberian sanksi bisa dengan penundaan tunjangan ataupun pembuatan makalah yang dipresentasikan langsung dimasyarakat. Juga bisa dilakukan pelepsan keanggotan jika permasalahan berkenaan dengan hukum. Pemberian sanksi diketahui oleh semua anggota Badan Kehormatan dan diusulkan dalam sidang paripurna DPRD. Pelaksanaan sanksi diawasi oleh tenaga ahli ataupun ketua sekretariat dewan. Badan Kehormatan juga berhak mencabut sanksi jika permasalahan hukum anggota dewan bisa diselesaiakan secara kekeluargaan. Dan tenaga ahli atau ketua sekretarian dewan memberikan penilaian berperilaku baik.

\section{Simpulan}

Badan Kehormatan (BK) merupakan alat kelengkapan DPRD yang dibentuk untuk menegakan kode etik DPRD. Namun di DPRD Kabupaten Pemalang belum ada aturan tetap tentang kode etik. Pada dasarnya Badan Kehormatan merupakan lembaga pengawasan internal DPRD. Fungsi badan kehormatan ada 2 (dua), yatu fungsi aktif dan fungsi pasif. Fungsi aktif BK yaitu fungsi pengawasan yang dalam hal ini Badan Kehormatan

29 Alfonso Donoso, “Commentaries on Criminal Law Conversations", Criminal Law and Philosophy Vol. 9, Issue. 2, (June 2015): 338. 
mengevaluasi absensi, produk hukum yang dihasilkan oleh DPRD, dan intensitas rapat yang dilakukan oleh anggota dewan. Fungsi pasif Badan Kehormatan yaitu tindakan Badan Kehormatan menindaklanjuti ketika ada pengaduan adanya indikasi pelanggaran oleh anggota dewan.

Badan Kehormatan selalu memberi himbauan kepada anggota-anggota dewan agar tidak melakukan pelanggaran ataupun tindakan penyimpangan. Mengenai peran fungsi Badan Kehormatan DPRD Kabupaten Pemalang dalam penegakan etika Anggota DPRD periode 2014-2019, pada dasarnya Badan Kehormatan sebagai badan pemerintahan daerah belum bekerja dengan baik. Dengan demikian peran fungsi Badan Kehormatan dalam penegakan kode etik belum maksimal dan belum sesuai dengan apa yang diharapkan. Tidak adanya pola pengawasan secara berkala terhadap tiap anggota DPRD.

Faktor penghambat Badan Kehormatan dalam menjalankan fungsinya antara lain: tidak adanya aturan khusus recruitment anggota Badan Kehormatan, lemahnya tata tertib DPRD, terbentur tidak adanya Pedoman Tata Beracara Badan Kehormatan, masalah prosedural pengaduan yang rumit, pengadu kurang bekerjasama, dan adanya sifat Solidaritas antar anggota DPRD. Dalam menghadapi faktor-faktor tersebut, Badan Kehormatan berupaya lebih aktif dalam mengamati tingkah laku anggota dewan baik di kantor maupun di luar kantor. Selain itu Badan Kehormatan juga lebih mengoptimalkan sarana dan prasarana yang ada dan dapat mendukung kinerja Badan Kehormatan.

\section{DAFTAR PUSTAKA}

\section{Buku}

Asshiddiqie, Jimly. Pengantar Ilmu Hukum Tata Negara. Jakarta: Rajawali Pers, 2011.

\begin{tabular}{c} 
Pergumulan Peran \\
\hline Pemerintah dan Parlemen Dalam \\
Sejarah. Jakarta: UI Press, 1996.
\end{tabular}

Moleong, Lexy J. Metodologi Penelitian

Kualitatif. Bandung: Rosda Karya, 2010.

Muhammad, Abdulkadir. Etika Profesi Hukum. Bandung: Citra Aditya Bakti, 2006.
Murhani, Suriansyah. Aspek Hukum Pengawasan Pemerinta Daerah. Yogyakarta: Laksbang Mediatama, 2008.

Soekanto, Soerjono. Pengantar Penelitian Hukum. Jakarta: UI Press, 2005. - Sosiologi Suatu Pengantar. Jakarta: Rajawali Pers, 2009.

Sunggono, Bambang. Metodologi Penelitian Hukum. Jakarta: RajaGrafindo Persada, 2012. 


\section{Jurnal}

Adeney, Katharine and Paul Taggart. "Introduction: The Future of Democracy". Government and Opposition, Vol. 50, Issue 3, (2015): 327.

Armytage , James Green. "Direct Voting And Proxy Voting". Constitutional Political Economy Vol. 26, Issue 2, (June 2015): 210.

Costa, Antonio Carlos Rocha. "Situated Legal Systems And Their Operational Semantics". Journal Artificial Intelligence and Law Vol. 23, Issue 1, (March 2015): 51.

Donoso, Alfonso "Commentaries on Criminal Law Conversations". Criminal Law and Philosophy Vol. 9, Issue 2, (June 2015): 338 .

H. James Alm, R. Dkk. "Can Indonesia Decentralise Successfully? Plans Problems and Prospects". Bulletin of Indonesian Economic Studies Vol. 37, Issue 1, (February 2001): 3.

Krug, Barbara dan Alexander Libman. "Commitment To Local Autonomy In Non-Democracies Russia And China Compared". Constitutional Political Economy Vol. 26, Issue 3, (June, 2015): 224.

Leonard, Eric K. "Global Governance and the State: Domestic Enforcement of Universal Jurisdiction". Human Right Review Vol. 16, Issue 2, (June 2015): 150.
Liebwald, Doris. “On Transparent Law, Good Legislation And Accessibility To Legal Information: Towards An Integrated Legal Information System”. Artificial Intelligence and Law Vol. 23, Issue 3, (September 2015): 308.

Marulak Pardede Team. "Efektivitas Putusan Badan Kehormatan DPR/DPRD”. Badan Pembinaan Hukum Nasional Kementerian Hukum Dan HAM - RI, (2011): 45.

MD., Mahfud. "Capaian dan Proyeksi Hukum Indonesia". Jurnal Hukum Vol. 16, No. 3, (Juli 2009): 291 - 310.

Morrison, Alan D. and William J. Wilhelm Jr."Trust, Reputation, And Law: The Evolution Of Commitment In Investment Banking”. Journal of Legal Analysis Vol. 7, Issue 2, (2015): 368.

Paldam, Martim. "The Public Choice Of University Organization: A Stylized Story Of A Constitutional Reform". Constitutional Political Economy Vol. 26, Issue 2, (June 2015): 151.

Pietsch, Juliet And Marshall Clark. "Critical Citizens: Attitudes towards Democracy in Indonesia and Malaysia”. Japanese Journal of Political Science Vol. 16, Issue 2, (2015): 202.

Pitsoulis, Athanassios and Steffen W. Groß. "The Other Side Of The Argument": Isaiah Berlin Versus F. A. Von Hayek on Liberty, Public Policies and The Market”. Constitutional Political 
Economy Vol. 26, Issue 4, (December 2015): 15 .

Rahim, Lily Zubaidah dan Juliet Pietsch "Introduction: States, Critical Citizens, and the Challenge of Democratization in Southeast Asia". Japanese Journal of Political Science Vol. 16, Issue 2, Cambridge University Press, (2015): 141.

Schlosser, Dirk Berg. "The Emergence of Democracy: Forces and Counterforces". Government and Opposition, Vol. 50, Issue 3, (Juli 2015): 337.

Sorge, Marco M. "Lobbying (Strategically Appointed) Bureaucrats" Constitutional
Political Economy Vol. 26, Issue 2, (June 2015): 174.

Tiedemann, Paul. "Is There a Human Right to Freedom of Religion?". Human Rights Review Vol. 16, Issue 2, (June 2015): 89.

Traversa, Federico. "Income And The Stability Of Democracy: Pushing Beyond The Borders Of Logic To Explain A Strong Correlation?". Constitutional Political Economy Vol. 26, Issue 2, (June 2015): 131.

Waylen, Georgina. "Engendering the 'Crisis of Democracy': Institutions, Representation and Participation". Government and Opposition Vol. 50, Issue 3, (July 2015): 495. 